\title{
Rescue Therapy in Patient with Glioblastoma Multiforme Combining Chemotherapy, Hyperthermia, Phytotherapy
}

\section{Carlo Pastore ${ }^{1}$, Massimo Fioranelli ${ }^{2 *}$ and Maria Grazia Roccia ${ }^{2}$}

${ }^{1}$ Department of Oncology, Casa di Cura Villa Salaria, Italy

${ }^{2}$ Department of Cardiology, University of Guglielmo Marconi, Italy

*Corresponding author: Massimo Fioranelli, Department of Cardiology, University of Guglielmo Marconi, Italy, Tel: +39068557844; E-mail: massimo.fioranelli@gmail.com

Received Date: October 18, 2017; Accepted Date: November 14, 2017; Published Date: November 20, 2017

Copyright: ( 2017 Pastore C, et al. This is an open-access article distributed under the terms of the Creative Commons Attribution License, which permits unrestricted use, distribution, and reproduction in any medium, provided the original author and source are credited.

\begin{abstract}
Glioblastoma multiforme is a pathology that is poorly treatable and tends towards recurrence. If surgically unresectable, at least without macroscopically visible residue, the prognosis is severe. Here is the case of a 60-yearold woman suffering from recurrent glioblastoma who comes to my observation with no therapeutic options and treated with a combination of antiangiogenic drug, RF capacitive hyperthermia and herbal medicine, earns an acceptable quality of life and survival prolongation of six months.
\end{abstract}

\section{Keywords: Glioblastoma; Chemotherapy; Oncological} hyperthermia; Phytotherapy

\section{Introduction}

The high grade brain tumors predominantly affect adults and have a high biological aggressiveness. It is difficult to get a remission after the second line drug therapy [1]. In this article carry over the experience with a woman with recurrent glioblastoma deemed eligible only palliative therapy after the second line therapy. A third line set with antiangiogenic drug, capacitive hyperthermia and herbal medicine has achieved a significant improvement in the general condition and prolonged survival of six months.

\section{Case Report}

Mrs. M.T. came to my observation for severe neutropenia following administration of fotemustine for relapsed glioblastoma fotemustine $[2,3]$. The diagnosis had been made a year before and had undergone a first surgery, radiotherapy/adjuvant chemotherapy with temozolomide, a new surgery for recurrence and residue further chemotherapy with fotemustine. For medullary impact in another therapeutic Institute had seen fit to suspend it for palliative therapy. The haematochemical and general condition improvement after strong supportive therapy lead to set a new specific treatment with bevacizumab [4,5] (tri-weekly basis and at a dose of $10 \mathrm{mg} / \mathrm{kg}$ ), capacitive hyperthermia every other day (55 minutes each therapeutic session) [6-8], curcumin (100 mg four times daily) [9,10], Boswellia serrata (400 $\mathrm{mg}$ four times daily) [11]. Control MRI with mdc every 3 months. After the first RMN has verified a reduction from $6 \times 5 \mathrm{~cm}$ to $2.4 \times 2.5$ with marked improvement in overall condition (Figure 1). The second MRI showed stability. The patient died a few days after arrival for acute intractable cryptogenic pulmonary oedema.

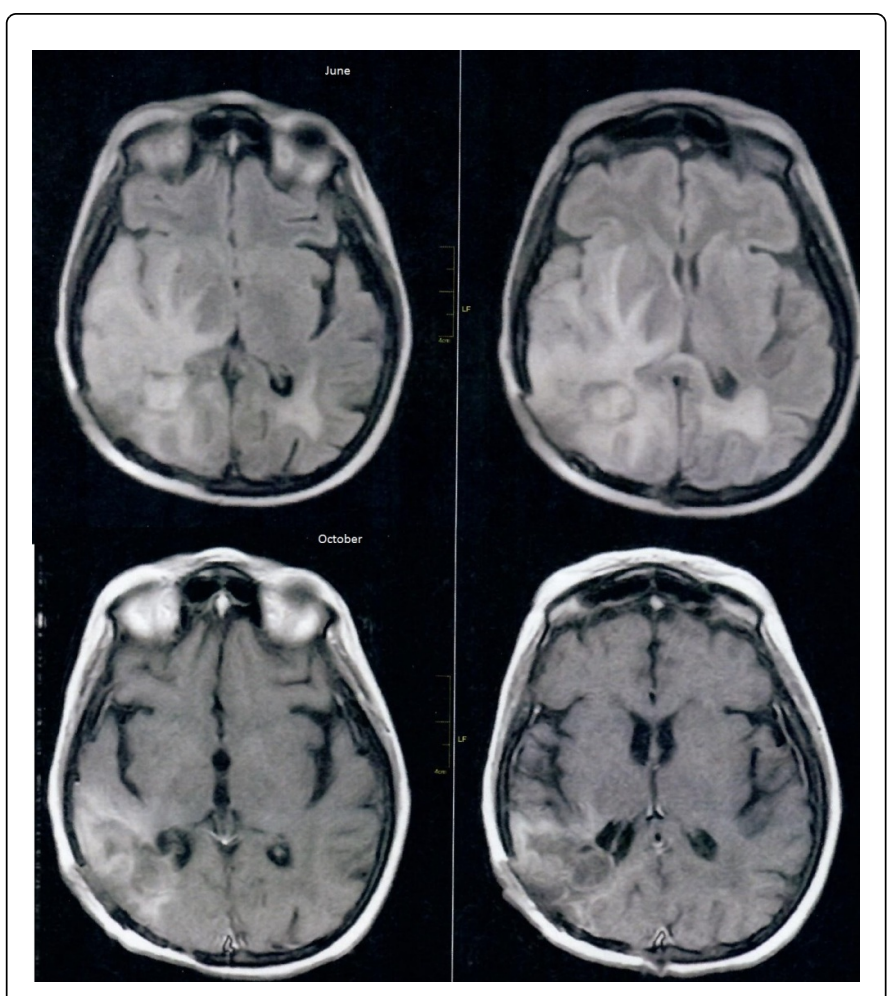

Figure 1: MRI scan of the patient.

\section{Discussion}

Glioblastoma multiforme is a neoplastic form with scarcity of treatment options besides surgery that unfortunately rarely can be defined as radical. Drugs considered most active are the temozolomide and fotemustine [12]. Antiangiogenic and particularly the bevacizumab appear promising but not used in first line therapy. Interesting in my opinion an opportunity to combine an 
Citation: Pastore C, Fioranelli M, Roccia MG (2017) Rescue Therapy in Patient with Glioblastoma Multiforme Combining Chemotherapy, Hyperthermia, Phytotherapy. J Integr Oncol 6: 199. doi:10.4172/2329-6771.1000199

Page 2 of 2

antiangiogenic therapy as bevacizumab (presenting good tolerability but a very limited duration of action in time, no impact alone on overall survival, especially in pre-treated Patients [13,14] with a physical therapy which radiofrequency hyperthermia and ancillary therapy with herbal medicines with specific action pro-apoptotic and anti-edema. A single event cannot define anything conclusive but can be interesting inspiration for further study.

\section{References}

1. Birk HS, Han SJ, Butowski NA (2017) Treatment options for recurrent high-grade gliomas. CNS Oncol 6: 61-70.

2. Segura P, Manneh R, Ceballos I, Garcia A, Benavides M, et al. (2016) GEINOFOTE: efficacy and safety of fotemustine in patients with highgrade recurrent gliomas and poor performance status. Clin Transl Oncol 18: 805-812.

3. Silvani A, Gaviani P, Lamperti E, Botturi A, Ferrari D, et al. (2011) Lecture: fotemustine in brain tumors. Neurol Sci 32: S255-S257.

4. Yu Z, Zhao G, Zhang Z, Li Y, Chen Y, et al. (2016) Efficacy and safety of bevacizumab for the treatment of glioblastoma. Exp Ther Med 11: 371-380.

5. Plate KH, Scholz A, Dumont DJ (2012) Tumor angiogenesis and antiangiogenic therapy in malignant gliomas revisited. Acta Neuropathol 124 763-775.

6. Oei AL, Vriend LE, Krawczyk PM, Horsman MR, Franken NA, et al. (2017) Targeting therapy-resistant cancer stem cells by hyperthermia. Int J Hyperthermia 2: 1-12.
7. Datta NR, Ordóñez SG, Gaipl US, Paulides MM, Crezee H, et al. (2015) Local hyperthermia combined with radiotherapy and-/or chemotherapy: recent advances and promises for the future. Cancer Treat Rev 41: 742-753.

8. Sun J, Guo M, Pang H, Qi J, Zhang J, et al. (2013) Treatment of malignant glioma using hyperthermia. Neural Regen Res 8: 2775-2782.

9. Klinger NV, Mittal S (2016) Therapeutic Potential of Curcumin for the Treatment of Brain Tumors. Oxid Med Cell Longev 2016: 9324085.

10. Luthra PM, Lal N (2015) Prospective of curcumin, a pleiotropic signalling molecule from Curcuma longa in the treatment of Glioblastoma. Eur J Med Chem 15: 23-35.

11. Kirste S, Treier M, Wehrle SJ, Becker G, Abdel-Tawab M, et al. (2011) Boswellia serrata acts on cerebral edema in patients irradiated for brain tumors: a prospective, randomized, placebo-controlled, double-blind pilot trial. Cancer 117: 3788-3795.

12. Venur VA, Peereboom DM, Ahluwalia MS (2015) Current medical treatment of glioblastoma. Cancer Treat Res 163: 103-115.

13. De Lemos ML, Markarian A, Chan E, Schaff K, Walisser S (2016) Clinical effectiveness of bevacizumab in patients with recurrent brain tumours: A population-based evaluation. J Oncol Pharm Pract pii: 1078155216681191.

14. Wang N, Jain RK, Batchelor TT (2017) New directions in anti-angiogenic therapy for glioblastoma. Neurotherapeutics 14: 321-332. 